\title{
PENGARUH KONFLIK DAN KECERDASAN EMOSIONAL TERHADAP KINERJA PERAWAT WANITA YANG SUDAH MENIKAH PADA RSUD DR. ADJIDARMO RANGKASBITUNG
}

\author{
Kris Dipayanti ${ }^{*}$, Indri Rahma Pertiwi ${ }^{\star *}$ \\ Email : krisdy290208@yahoo.com
}

\begin{abstract}
ABSTRAK
Pengaruh Konflik Dan Kecerdasan Emosional Terhadap Kinerja Perawat Wanita Yang Sudah Menikah Pada RSUD Dr. Adjidarmo Rangkasbitung. Penelitian ini bertujuan untuk mengetahui seberapa besar pengaruh konflik dan kecerdasan emosional terhadap kinerja perawat wanita, dan yang menjadi objek dalam penelitian ini adalah perawat wanita yang sudah menikah pada RSUD Dr. Adjidarmo Rangkasbitung. Metode yang digunakan deskriftif dengan pendekatan kuantitatif, dengan sampel 52 responden, metode analisis dengan menghitung uji validitas, uji reliabilitas,analisis regresi linier berganda, koefisien korelasi berganda, koefisien determinasi, uji t dan uji f dan untuk uji klasiknya adalah uji normalitas, uji homogenitas dan uji multikolinieritas. Berdasarkan hasil perhitungan analisis regresi berganda diperoleh $Y=3,154+$ $0,273(\mathrm{X} 1)+0,620(\mathrm{X} 2)$, dimana kinerja perawat (Y), konflik (X1) dan kecerdasan emosional (X2) diuji menggunakan uji t menunjukkan bahwa kedua variabel independen secara signifikan mempengaruhi kinerja perawat $(\mathrm{Y})$ sebagai variabel dependen. Kemudian melalui uji koefisien determinasi menunjukkan $\mathrm{R}$ sebesar 0,863 yang berarti terdapat hubungan yang positif dan kuat antara konflik dan kecerdasan emosional pada kinerja perawat. Koefisien determinasinya sebesar 0,745 . Hal ini menunjukkan sebesar $74,5 \%$, sedangkan $25,5 \%$ dipengaruhi oleh faktor lain yang tidak diteliti. Berdasarkan pengujian hipotesis yang telah dilakukan dengan menggunakan uji $\mathrm{F}$ diperoleh bahwa $\mathrm{F}_{\text {hitung }}=71,472$ dan setelah dikonsultasikan dengan $\mathrm{F}_{\text {tabel }}$ pada taraf signifikasi $10 \%$ menunjukkan $F_{\text {tabel }}=2,41$ yang artinya terdapat pengaruh yang positif dan signifikan antara konflik dan kecerdasan emosional terhadap kinerja perawat karena $\mathrm{F}_{\text {hitung }}$ $(71,472)>F_{\text {tabel }}(2,41)$. Hasil penelitian ini disimpulkan terdapat pengaruh yang positif dan signifikan antara Konflik $\left(\mathrm{X}_{1}\right)$ dan Kecerdasan Emosional $\left(\mathrm{X}_{2}\right)$ secara simultan terhadap Kinerja perawat $(Y)$.
\end{abstract}

Kata kunci : Konflik, Kecerdasan Emosional Dan Kinerja Perawat

\begin{abstract}
This research aims to find out how big the influence of conflict and emotional intelligence on performance of women, and nurses who become objects in this research is a nurse married women at the Provincial Hospital Dr. Adjidarmo Rangkasbitung. The methods used to deskriftif with a quantitative approach, with a sample of 52 respondents, methods of analysis by calculating the validity test, reliability test, multiple linear regression analysis, correlation coefficient, coefficient of multiple determination, $t$ test and $f$ test and for his classic test is a test of normality, test its homogeneity and test multikolinieritas. Based on the results of multiple regression analysis calculation obtained $3.154+Y=0.273(X 1)+0.620(X 2)$, where the performance of nurses $(Y)$, conflict $(X \quad 1)$ and emotional intelligence $(X$ 2) were tested using t-test showed that the two independent variables significantly affect the performance of nurses $(Y)$ as the dependent variable. Then the coefficient of determination $R$ of 0.863 shows which means there is a strong and positive relationship between conflict and emotional intelligence on the performance of the nurses. Determinasinya coefficient of 0.745 . This shows amounted to $74.5 \%, 25.5 \%$ are influenced by other factors not examined. Based on hypothesis testing that has been done by using the $f$ test is obtained that the $F_{\text {count }}=71.472$, and after should be referred with $F_{\text {table }}$ on the significance of level $10 \%$ showed the $F_{\text {table }}=2.41$, meaning there are influences a positive and significant between conflict and emotional intelligence on performance of nurses because of the $F_{\text {count }}(71.472)>F_{\text {table }}(2.41)$. The results of this research concluded there is a significant and positive influence on the Conflict between $\left(X_{1}\right)$ and emotional intelligence $\left(X_{2}\right)$ simultaneously on performance of nurses $(Y)$
\end{abstract}

Keywords: Conflict, emotional intelligence and performance of Nurses

*) dan **) Dosen Universitas Pamulang 


\section{PENDAHULUAN.}

\section{A. Latar Belakang Masalah}

Pada era globalisasi seperti saat ini, emansipasi wanita bukanlah hal asing yang sering didengar. Kesejajaran kedudukan antara wanita dengan pria sudah tidak menjadi kendala bagi wanita untuk melakukan pekerjaan yang biasa dilakukan oleh pria seperti halnya mencari nafkah atau bekerja. Salah satu Instansi yang terdapat banyak sekali pekerja wanita yaitu di Bidang Kesehatan seperti di Rumah sakit.

Rumah sakit adalah salah satu sarana pelayanan kesehatan yang sering dimanfaatkan oleh masyarakat dalam mencari bantuan terhadap permasalahan kesehatan. Keberhasilan rumah sakit dalam menjalankan fungsinya ditandai dengan adanya peningkatan mutu pelayanan rumah sakit. Mutu rumah sakit sangat dipengaruhi oleh beberapa faktor. Faktor yang paling dominan adalah sumber daya manusia. Menurut UU RI No. 36 tahun 2009 tentang kesehatan, tenaga kesehatan dikelompokkan sesuai keahlian yang dimiliki seperti tenaga medis, tenaga farmasi, tenaga keperawatan, tenaga masyarakat dan lingkungan, tenaga gizi, tenaga keterampilan fisik, tenaga keteknisan dan lain-lainnya yang menunjang dalam pemberian jasa kesehatan. Pelaksanaan prosedur rumah sakit adalah penerimaan pasien rawat inap, mempersiapkan pasien yang akan pulang, rujukan dan penggunaan alat medik dan keperawatan.

Berdasarkan besarnya jumlah perawat yang bertugas di rumah sakit, terlihat bahwa perawat memegang peranan yang sangat besar dalam bidang pelayanan kesehatan. Menurut pendapat Kepala Keperawatan RSUD Dr. Adjidarmo rangkasbitung rendahnya kinerja perawat wanita yang sudah menikah disebabkan adanya faktor konflik. Konflik yang dimaksud disini yaitu konflik mengenai antara konflik pekerjaan dengan keluarga. Konflik yang dialami wanita karir dan juga sekaligus sebagai ibu rumah tangga yang harus bertanggung jawab mengurus keluarganya. Hal ini seringkali menimbulkan konflik ketika wanita yang bekerja menghadapi berbagai kendala dalam rumah tangganya dan hal ini akan berimbas kepada kinerja yang dihasilkan. Hal ini terutama berlaku pada wanita yang memiliki beban pekerjaan yang cukup tinggi serta bekerja dibawah tekanan.

Konflik peran ganda merupakan konflik yang terjadi pada pegawai, dimana di satu sisi wanita harus melakukan pekerjaan di kantor, sedangkan di sisi lain wanita harus memperhatikan keluarga secara utuh, sehingga sulit untuk membedakan antara pekerjaan mengganggu keluarga dan keluarga mengganggu pekerjaan. Pekerjaan sebagai perawat tidak mudah dilakukan oleh wanita yang telah menikah dan memiliki anak karena mereka dituntut untuk dapat menjalankan perannya sebaik mungkin sebagai pekerja dan juga ibu rumah tangga. Adanya tuntutan pekerjaan seperti jumlah jam kerja, beban kerja dan shift kerja secara positif sangat diasosiasikan dengan konflik peran ganda. Konflik peran ganda menimbulkan dampak negatif, baik terhadap wanita bekerja itu sendiri, keluarganya, maupun bagi organisasi tempat dia bekerja. Beberapa dampak negatif secara individual di antaranya adalah menurunkan kinerja dalam kehidupan rumah tangga, ketegangan dan stres pada diri wanita bekerja, gangguan kesehatan dan ketidak harmonisan hubungan dengan anggota keluarga lain. 
Berdasarkan hasil wawancara yang dilakukan kepada perawat wanita yang sudah menikah yang bekerja di RSUD Dr. Adjidarmo Rangkasbitung pada tanggal 06 Agustus 2018, diketahui bahwa konflik yang terjadi di RSUD Dr. Adjidarmo Rangkasbitung tergolong tinggi sebagai berikut:

Tabel 1.1 : Data Konflik Perawat Wanita Yang Sudah Menikah di RSUD Dr. Adjidarmo Rangkasbitung

\begin{tabular}{|c|l|c|c|c|}
\hline No. & \multicolumn{1}{|c|}{ Pertanyaan } & Ya & Tidak & Jumlah \\
\hline 1. & $\begin{array}{l}\text { Anda merasa terganggu waktunya bersama keluarga } \\
\text { saat anda disuruh masuk saat libur }\end{array}$ & 87 & 22 & 109 \\
\hline 2. & Waktu kerja membuat anda tertekan & 72 & 37 & 109 \\
\hline 3. & $\begin{array}{l}\text { Masalah dengan keluarga membuat anda tidak } \\
\text { maksimal dalam bekerja, sehingga menimbulkan sikap } \\
\text { yg tidak ramah terhadap pasien }\end{array}$ & 95 & 14 & 109 \\
\hline
\end{tabular}

Sumber: Hasil survai Bagian Keperawatan RSUD Dr. Adjidarmo, Rangkasbitung.

Berdasarkan hasil wawancara di atas yang dilakukan kepada perawat wanita yang sudah menikah yang bekerja di RSUD Dr. Adjidarmo Rangkasbitung, diketahui bahwa konflik peran ganda muncul ketika perawat wanita yang sudah menikah sering datang terlambat karena harus mengurus anak dan melakukan tugas ibu rumah tangga lainnya seperti memasak, mencuci, membersihkan rumah, mengurus anak dan mengurus keperluan suami pada pagi hari.

Waktu kerja membuat perawat tertekan, karena perawat wanita yang sudah menikah sulit untuk berkonsentrasi dengan kebutuhan pasien dan terkadang meninggalkan pasien dengan teman satu shift karena kondisi anak sedang rewel dan sakit di rumah. Perawat juga mengatakan bahwa ketika pulang ke rumah, perawat harus tetap mengerjakan pekerjaan rumah walaupun dengan sangat lelah, namun sebagai seorang ibu rumah tangga, pekerjaan rumah tangga akan selalu ada apalagi jika mempunyai anak kecil. Perawat pun sering menitipkan anak di TPA (Tempat Penitipan Anak). Sebagai seorang ibu, perawat merasa kasihan karena anaknya sering ditinggal dan sering merasa cemas jika kondisi anak sedang sakit dan sering meminta izin kepada kepala perawat untuk melihat anak di TPA.

Menurut pendapat Kepala Keperawatan RSUD Dr. Adjidarmo Rangkasbitung faktor kedua yang mempengaruhi kinerja perawat wanita yang sudah menikah di RSUD Dr. Adjidarmo Rangkasbitung adalah kecerdasan emosional. Berdasarkan hasil wawancara yang dilakukan kepada perawat wanita yang sudah menikah yang bekerja di RSUD Dr. Adjidarmo Rangkasbitung pada tanggal 06 Agustus 2018, diketahui bahwa masalah Kecerdasan Emosional yang terjadi di RSUD Dr. Adjidarmo Rangkasbitung tergolong tinggi sebagai berikut:

Tabel 1.2 : Data Kecerdasan Emosional Perawat Yang Sudah Menikah di RSUD Dr. Adjidarmo Rangkasbitung

\begin{tabular}{|c|l|c|c|c|}
\hline No. & \multicolumn{1}{|c|}{ Pertanyaan } & lya & Tidak & Jumlah \\
\hline 1. & $\begin{array}{l}\text { Perasaan emosional dapat mempengaruhi } \\
\text { pikiran, perkataan, dan perbuatan ketika } \\
\text { sedang bekerja }\end{array}$ & 98 & 11 & 109 \\
\hline 2. & $\begin{array}{l}\text { Anda dapat berpikir jernih dan memusatkan } \\
\text { perhatian pada apa yang sedang anda } \\
\text { kerjakan saat anda dalam keadaan marah }\end{array}$ & 13 & 96 & 109 \\
\hline 3. & $\begin{array}{l}\text { Anda dapat menjadi pendengar yang baik } \\
\text { saat teman-teman anda yang sedang } \\
\text { mengalami masalah }\end{array}$ & 22 & 87 & 109 \\
\hline
\end{tabular}

Sumber: Hasil Survai Bagian Keperawatan RSUD Dr. Adjidarmo, Rangkasbitung. 
Berdasarkan tabel 1.2 di atas bahwa perasaan emosional dapat mempengaruhi pikiran, perkataan, dan perbuatan ketika sedang bekerja, seperti penjelasan di atas bahawasannya jika para perawat mempunyai masalah pribadi di rumah, jika tidak ada sikap profesional dalam bekerja maka bisa berimbas pada prilaku dan sikap kurang ramah pada pasien. Perawat tidak dapat berpikir jernih dan memusatkan perhatian pada apa yang sedang anda kerjakan saat anda dalam keadaan marah, karena pengaruh ketidak fokusan terhadap peranannya sebagai seorang ibu rumah tangga di rumah dan sebagai pekerja di rumah sakit, sebagian besar mereka kurang profesional untuk bisa mengendalikan permasalahan dan emosinya lebih berperan besar berpengaruh terhadap prilaku perawat dan kurang bisa menjadi pendengar yang baik saat temanteman anda yang sedang mengalami masalah, karena masalah emosi tadi.

Kecerdasan emosional merupakan faktor penting yang harus diperhatikan oleh perawat karena perawat merupakan pegawai rumah sakit yang kinerjanya banyak terlibat langsung dengan pasien. Kecerdasan emosional menyumbang $80 \%$ dari faktor penentu kesuksesan seseorang, sedangkan 20\% yang lain ditentukan oleh IQ. Begitu pula disimpulkan oleh Joan Beck bahwa IQ sudah berkembang $50 \%$ sebelum usia lima tahun, $80 \%$ berkembangnya sebelum delapan tahun dan hanya berkembang $20 \%$ sampai akhir batas remaja, sedangkan kecerdasan emosional dapat dikembangkan tanpa batas waktu. Dengan demikian kecerdasan emosional berpengaruh terhadap kinerja pegawai. Berdasarkan survei yang dilakukan peneliti di RSUD Dr. Adjidarmo Rangkasbitung masih ditemukan banyak keluhan dari pasien/keluarga pasien tentang perawat yang kurang ramah saat berkomunikasi serta masih ada kecenderungan perawat bersikap emosional saat memberikan saran tentang kesehatan dan saat mendapat laporan keluhan dari pasiennya. Perawat juga sering bersikap emosional bahkan marah pada pasien kalau saran dan anjurannya tidak dilaksanakan oleh pasien.

Penelitian ini dilaksanakan di RSUD Dr. Adjidarmo, Rangkasbitung yang berada di Jl. Iko Jatmiko No.1 Rangkasbitung, Lebak-Banten. Rumah sakit ini memiliki 9 layanan yaitu : instalasi laboratorium (24 jam), insttalasi gizi, instalasi radiologi, instalasi CSSD dan laundry, instalasi pemeliharaan sarana RS (IPSRS), instalasi sanitasi, apotik/instalasi farmasi (24 jam), fisioterapi dan CT Scan. Respondem dalam penelitian ini adalah perawat wanita RSUD Dr. Adjidarmo, Rangkasbitung. Jumlah Perawat wanita yang sudah menikah di RSUD Dr. Adjidarmo Rangkasbitung yaitu berjumlah 109 orang. Berdasarkan hasil wawancara peneliti dengan Kepala Keperawatan RSUD Dr. Adjidarmo Rangkasbitung mengatakan bahwa kinerja perawat wanita yang sudah menikah tergolong rendah sebagai beriku :

Tabel 1.3 : Data Penilaian Kinerja Perawat RSUD Dr. Adjidarmo Rangkasbitung Bulan Juli - Desember Tahun 2017

\begin{tabular}{|c|c|c|c|c|c|}
\hline No & Perilaku Kerja & Target & Bobot & Realisasi & Skor \\
\hline 1 & Tanggung Jawab & $80 \%$ & $15 \%$ & $50 \%$ & $3,3 \%$ \\
\hline 2 & Sikap Karyawan & $85 \%$ & $25 \%$ & $35 \%$ & $1,75 \%$ \\
\hline 3 & Kedisiplinan & $90 \%$ & $25 \%$ & $40 \%$ & $2 \%$ \\
\hline 4 & Kualitas Kerja & $85 \%$ & $10 \%$ & $60 \%$ & $6 \%$ \\
\hline 5 & Kuantitas & $75 \%$ & $10 \%$ & $50 \%$ & $5 \%$ \\
\hline 6 & Kerjasama & $80 \%$ & $15 \%$ & $40 \%$ & $2,67 \%$ \\
\hline \multicolumn{2}{r}{} & Total & $100 \%$ & Nilai pencapaian & $20,72 \%$ \\
\hline
\end{tabular}

Sumber : Bagian Keperawatan RSUD Dr. Adjidarmo, Rangkasbitung 
Berdasarkan hasil wawancara dengan perawat wanita yang sudah menikah, rendahnya kinerja perawat juga dapat dilihat dari sikap dan perilaku perawat dalam bekerja. Sikap dan perilaku terkait dengan tugas perawat untuk memberikan edukasi dan konseling terhadap pasien maupun keluarga pasien. Seperti memberikan edukasi kepada pasien maupun keluarga tentang hal-hal yang seharusnya dilakukan dan tidak dilakukan untuk pasien. Misalnya mengenai makanan atau tindakan yang diperbolehkan dan dilarang. Kenyataannya masih ada perawat yang tidak memberikan edukasi secara jelas kepada pasien maupun keluarga tentang hal-hal yang diperbolehkan dan yang tidak diperbolehkan.

Berdasarkan fakta yang diperoleh dari RSUD Dr. Adjidarmo Rangkasbitung tentang adanya beberapa perawat yang memiliki kinerja yang rendah, adanya konflik, rendahnya kecerdasan emosional, maka alasan tersebut yang mendasari penelitian ini mengambil judul "Pengaruh Konflik dan Kecerdasan Emosional Terhadap Kinerja Perawat Wanita Yang Sudah Menikah di RSUD Dr. Adjidarmo Rangkasbitung".

\section{B. Perumusan Masalah}

Berdasarkan latar belakang diatas, permasalahan yang dirumuskan dalam penelitian ini adalah sebagai berikut:

1. Seberapa besar pengaruh konflik terhadap kinerja pada perawat wanita yang sudah menikah di RSUD Dr. Adjidarmo Rangkasbitung?

2. Seberapa besar pengaruh kecerdasan emosional terhadap kinerja pada perawat wanita yang sudah menikah di RSUD Dr. Adjidarmo Rangkasbitung?

3. Seberapa besar pengaruh secara silmultan dari konflik dan kecerdasan emosional terhadap kinerja perawat yang sudah menikah di RSUD Dr. Adjidarmo Rangkasbitung?

\section{METODOLOGI PENELITIAN}

Pada penelitian ini peneliti melakuakan penelitian atau riset di RSUD Dr. Adjidarmo Rangkasbitung. Subyek penelitiannya adalah perawat wanita yang sudah menikah di RSUD Dr. Adjidarmo Rangkasbitung.

Penulis menggunakan metode penelitian diskriptif dengan pendekatan kuantitatif. Tujuan penelitian deskriptif adalah untuk membuat deskriptif, gambaran atau lukisan secara sistematis, faktual dan akurat mengenai fakta - fakta. Adapun populasi dalam penelitian adalah perawat wanita yang sudah menikah di RSUD Dr. Adjidarmo Rangkasbitung yang berjumlah 109 perawat wanita yang sudah menikah.

Teknik sampling untuk penentuan sampel yang digunakan dalam penelitian ini adalah random sampling dimana metode penarikan sampel dilakukan dengan cara acak sederhana dan setiap responden memiliki kemungkinan yang sama untuk terpilih sebagai responden. Menggunakan rumus slovin dengan kesalahan 10\%. Metode pengumpulan data melalui studi pustaka (library research) dan studi lapangan (field research). Untuk memperoleh data yang relevan, akurat dan reliable dalam penelitian ini menggunakan dua macam sumber data yaitu sumber primer dan sumber sekunder. 


\section{HASIL DAN PEMBAHASAN}

\section{A. Karakteristik Responden}

Karakteristik responden yang diamati dalam penelitian ini meliputi: usia, masa kerja dan pendidikan. Deskripsi karakteristik responden disajikan sebagai berikut:

\section{Responden Berdasarkan Tingkat Pendidikan}

Tabel 3.1 : Karakteristik Responden Berdasarkan Pendidikan Terakhir

\begin{tabular}{|c|c|c|}
\hline Pendidikan Terakhir & Frekuensi & Presentase \\
\hline D3 Keperawatan & 40 & $77 \%$ \\
\hline S1 Keperawatan & 12 & $23 \%$ \\
\hline Jumlah & 52 & $100 \%$ \\
\hline
\end{tabular}

(Sumber : Data Primer 2018)

Berdasarkan tabel di atas, responden dalam penelitian ini responden dengan jumlah terbesar adalah lulusan D3 Keperawatan yaitu sebanyak 40 orang atau $77 \%$ dan lulusan S1 Keperawatan sebanyak 12 orang atau 23\%. Berdasarkan pendidikan terakhir menunjukkan bahwa sebagian besar perawat yang bekerja di RSUD Dr. Adjidarmo Rangkasbitung mengenyam pendidikan sampai dengan D3. Hal ini menunjukkan bahwa mayoritas yang menjadi perawat wanita RSUD Dr. Adjidarmo Rangkasbitung berpendidikan D3 Keperawatan (77\%).

\section{Responden Berdasarkan Usia}

Tabel 3.2 : Karakteristik Responden Berdasarkan Usia

\begin{tabular}{|c|c|c|}
\hline Umur & Frekuensi & Presentase \\
\hline $20-30$ Tahun & 14 & $27 \%$ \\
\hline $31-40$ Tahun & 38 & $73 \%$ \\
\hline$\geq 40$ Tahun & - & - \\
\hline Jumlah & 52 & $100 \%$ \\
\hline
\end{tabular}

(Sumber : Data Primer 2018)

Karakteristik responden berdasarkan usia dapat diketahui sebanyak 27\% atau 14 orang berusia antara 20-30 tahun, 73\% atau 38 orang berusia antara 31-40 tahun dan tidak ada perawat wanita yang di atas usia 40 tahun. Seperti yang tertera pada tabel 4.2 di atas dapat diketahui bahwa responden yang bekerja di RSUD Dr. Adjidarmo Rangkasbitung sebagian besar berusia antara 31-40 tahun.

\section{Responden Berdasarkan Lama Bekerja}

Tabel 3.3 : Karakteristik Responden Berdasarkan Lama Bekerja

\begin{tabular}{|c|c|c|}
\hline Lama Kerja & Frekuensi & Presentase \\
\hline $1-5$ Tahun & 29 & $56 \%$ \\
\hline $6-10$ Tahun & 18 & $35 \%$ \\
\hline$\geq 11$ Tahun & 5 & $9 \%$ \\
\hline Jumlah & 52 & $100 \%$ \\
\hline
\end{tabular}

(Sumber : Data Primer 2018)

Berdasarkan tabel 4.3 dapat dilihat bahwa masa kerja sebagian besar perawat wanita yang sudah menikah di RSUD Dr. Adjidarmo Rangkasbitung yang menjadi responden dalam penelitian ini adalah sebesar $56 \%$ perawat wanita bekerja selama 1 5 Tahun. Perawat wanita yang bekerja antara 6 sampai 10 tahun adalah 18 orang atau $35 \%$ dan perawat wanita yang bekerja di atas 11 Tahun adalah 5 orang atau $9 \%$. 


\section{B. Hasil Analisis Deskriptif}

1. Deskripsi Konflik

Tabel 3.4 : Perhitungan Responden pada Variabel Konflik



(Sumber : Data Primer 2018) 
Berdasarkan data tabel di atas, rata-rata skor konflik sebesar 4,62 masuk pada interval 3,40-4,19 dengan interpretasi sangat tinggi yang artinya responden mempunyai persepsi bahwa terhadap konflik yang terjadi pada perawat wanita yang sudah menikah di RSUD Dr. Adjidarmo Rangkasbitung.

\section{Deskripsi Kecerdasan Emosional}

Tabel 3.5 Perhitungan Responden pada Variabel Kecerdasan Emosional

\begin{tabular}{|c|c|c|c|c|c|c|c|c|c|c|}
\hline \multirow{2}{*}{ No } & \multirow{2}{*}{ Pernyataan } & SS & S & $\mathbf{R}$ & TS & STS & \multirow{2}{*}{ Total } & \multirow{2}{*}{\begin{tabular}{|l} 
Total \\
Skor
\end{tabular}} & \multirow{2}{*}{$\begin{array}{l}\text { Rata2 } \\
\text { Skor }\end{array}$} & \multirow[t]{2}{*}{ KET } \\
\hline & & 5 & 4 & 3 & 2 & 1 & & & & \\
\hline \multicolumn{11}{|c|}{ Kesadaran emosi diri } \\
\hline 1 & $\begin{array}{l}\text { Saat melakukan pekerjaan, saya } \\
\text { kurang merasa percaya diri dengan } \\
\text { kemampuan yang saya miliki. }\end{array}$ & 5 & 44 & 2 & 1 & 0 & 52 & 209 & 4,18 & B \\
\hline 2 & $\begin{array}{l}\text { Menyadari bahwa perasaan } \\
\text { emosional dapat memengaruhi } \\
\text { pikiran, perkataan dan perbuatan } \\
\text { ketika sedang bekerja. }\end{array}$ & 4 & 45 & 1 & 2 & 0 & 52 & 208 & 4,16 & $\mathbf{B}$ \\
\hline & $\mathbf{F}$ & 9 & 89 & 3 & 3 & 0 & 104 & 417 & 4,17 & B \\
\hline & $\%$ & 8 & 86 & 3 & 3 & 0 & 100 & & & \\
\hline \multicolumn{11}{|c|}{ Pengelolaan Diri } \\
\hline 3 & $\begin{array}{l}\text { Saya belum mengetahui kelebihan } \\
\text { yang ada pada diri saya ketika } \\
\text { sedang menghadapi masalah. }\end{array}$ & 11 & 38 & 1 & 2 & 0 & 52 & 214 & 4,28 & SB \\
\hline 4 & $\begin{array}{l}\text { Belum bisa mengenali perasaan } \\
\text { saya ketika mengalami perubahan } \\
\text { suasana hati. }\end{array}$ & 10 & 38 & 3 & 1 & 0 & 52 & 213 & 4,26 & SB \\
\hline 5 & $\begin{array}{l}\text { Saya tidak bisa sangat tenang } \\
\text { meskipun dalam kondisi sangat } \\
\text { marah dengan orang lain. }\end{array}$ & 7 & 42 & 0 & 3 & 0 & 52 & 209 & 4,18 & B \\
\hline 6 & $\begin{array}{l}\text { Saat mengalami kegagalan, saya } \\
\text { mudah putus asa. }\end{array}$ & 6 & 42 & 2 & 2 & 0 & 52 & 208 & 4,16 & B \\
\hline 7 & $\begin{array}{l}\text { Jika sedang dalam keadaan marah, } \\
\text { saya tidak dapat berpikir jernih dan } \\
\text { memusatkan perhatian pada apa } \\
\text { yang sedang saya kerjakan. }\end{array}$ & 4 & 45 & 3 & 0 & 0 & 52 & 209 & 4,18 & B \\
\hline & $\mathbf{F}$ & 38 & 205 & 9 & 8 & 0 & 260 & 1053 & 4,21 & SB \\
\hline & $\%$ & 14,62 & 78,9 & 3,46 & 3,1 & 0 & 100 & & & \\
\hline \multicolumn{11}{|c|}{ Kesadaran Sosial } \\
\hline 8 & $\begin{array}{l}\text { Saya kurang bisa perhatikan } \\
\text { isyarat-isyarat emosi dari rekan } \\
\text { kerja dan sulit untuk membantu. }\end{array}$ & 5 & 43 & 4 & 0 & 0 & 52 & 209 & 4,18 & B \\
\hline 9 & $\begin{array}{l}\text { Kurang dalam membangun dan } \\
\text { memelihara hubungan informal } \\
\text { dengan rekan kerja atas dasar rasa } \\
\text { saling percaya dan kebersamaan. }\end{array}$ & 6 & 42 & 3 & 1 & 0 & 52 & 209 & 4,18 & B \\
\hline 10 & $\begin{array}{l}\text { Saya belum dapat menjadi pen- } \\
\text { dengar yang baik saat teman- } \\
\text { teman saya sedang berkeluh kesah. }\end{array}$ & 6 & 40 & 5 & 1 & 0 & 52 & 207 & 4,14 & $B$ \\
\hline & $\mathbf{F}$ & 17 & 125 & 12 & 2 & 0 & 156 & 625 & 4,16 & B \\
\hline & $\%$ & 43,3 & 50,1 & 3,85 & 1,92 & 0 & 100 & & & \\
\hline \multicolumn{2}{|c|}{ Total Jawaban } & 64 & 419 & 24 & 13 & 0 & 520 & & & \\
\hline & Persentase Jawaban (\%) & $\begin{array}{c}12,31 \\
\%\end{array}$ & $\begin{array}{c}80,58 \\
\%\end{array}$ & $\begin{array}{c}4,61 \\
\%\end{array}$ & $2,5 \%$ & $0 \%$ & $100 \%$ & Rata2 & 4,19 & B \\
\hline
\end{tabular}

(Sumber : Data Primer 2018) 
Berdasarkan data tabel di atas untuk penilaian responden atas pernyataan pada variabel kecerdasan emosional (X2), yang menjawab sangat setuju, setuju, kurang setuju, tidak setuju dan sangat tidak setuju sebesar $(12,31 \%+80,58 \%+4,61 \%+2,5 \%$ $+0 \%)=100 \%$ dengan rata - rata skor 4,19 termasuk pada tabel 3.4 untuk rentang skala 3.40 - 4.19 dengan kriteria baik. Maka untuk lebih baik lagi Kecerdasan Emosional di RSUD Dr. Adjidarmo Rangkasbitung perlu ditingkatkan lagi.

\section{Deskripsi Kinerja Perawat}

Tabel 3.6. : Perhitungan Responden pada Variabel Kinerja Perawat

\begin{tabular}{|c|c|c|c|c|c|c|c|c|c|c|}
\hline \multirow{2}{*}{ No } & \multirow{2}{*}{ Pernyataan } & \multirow{2}{*}{$\begin{array}{c}\text { SS } \\
5\end{array}$} & \multirow{2}{*}{$\begin{array}{l}S \\
4\end{array}$} & \multirow{2}{*}{$\begin{array}{l}\mathbf{R} \\
3\end{array}$} & \multirow{2}{*}{$\begin{array}{c}\text { TS } \\
2\end{array}$} & \multirow{2}{*}{$\begin{array}{c}\text { STS } \\
1\end{array}$} & \multirow{2}{*}{ Total } & Total & Rata2 & \multirow{2}{*}{ KET } \\
\hline & & & & & & & & Skor & Skor & \\
\hline \multicolumn{11}{|c|}{ Kuantitas Pekerjaan } \\
\hline 1 & $\begin{array}{l}\text { Belum mampu } \\
\text { menggunakan peralatan } \\
\text { medis dengan baik } \\
\text { sesuai prosedur. }\end{array}$ & 3 & 46 & 2 & 1 & 0 & 52 & 207 & 4,14 & B \\
\hline 2 & $\begin{array}{l}\text { Proses kerja yang saya } \\
\text { lakukan belum sesuai } \\
\text { dengan standar operasi } \\
\text { prosedur kerja. }\end{array}$ & 9 & 40 & 2 & 0 & 1 & 52 & 212 & 4,24 & SB \\
\hline & $\mathbf{F}$ & 12 & 86 & 4 & 1 & 1 & 104 & 316 & 4,19 & B \\
\hline & $\%$ & 11,54 & 82,7 & 3,85 & 0,96 & 0,96 & 100 & & & \\
\hline \multicolumn{11}{|c|}{ Kualitas Pekerjaan } \\
\hline 3 & $\begin{array}{l}\text { Kurang tepat waktu } \\
\text { dalam menangani pasien }\end{array}$ & 7 & 40 & 3 & 2 & 0 & 52 & 208 & 4,16 & B \\
\hline 4 & $\begin{array}{l}\text { Belum siap saat pasien } \\
\text { datang. }\end{array}$ & 6 & 43 & 1 & 2 & 0 & 52 & 209 & 4,18 & B \\
\hline & $\mathbf{F}$ & 13 & 83 & 4 & 4 & 0 & 104 & 417 & 4,17 & B \\
\hline & $\%$ & 12,5 & 80 & 3,9 & 3,9 & 0 & 100 & & & \\
\hline \multicolumn{11}{|c|}{ Ketepatan Waktu } \\
\hline 5 & $\begin{array}{l}\text { Belum dapat menyele- } \\
\text { saikan pekerjaan sesuai } \\
\text { waktu dan prosedur } \\
\text { yang ditentukan. }\end{array}$ & 7 & 42 & 2 & 1 & 0 & 52 & 211 & 4,22 & SB \\
\hline 6 & $\begin{array}{l}\text { Belum bisa mengguna- } \\
\text { kan waktu kerja seefektif } \\
\text { mungkin dalam } \\
\text { menangani pekerjaan. }\end{array}$ & 5 & 43 & 2 & 2 & 0 & 52 & 207 & 4,14 & B \\
\hline & $\mathbf{F}$ & 12 & 85 & 4 & 3 & 0 & 104 & 418 & 4,18 & $\mathbf{B}$ \\
\hline & $\%$ & 11,54 & 82 & 3,85 & 2,88 & 0 & 100 & & & \\
\hline \multicolumn{11}{|c|}{ Kehadiran } \\
\hline 7 & Kurang hadir tepat waktu & 4 & 46 & 1 & 0 & 1 & 52 & 208 & 4,16 & B \\
\hline 8 & Absen ketika jam kerja. & 6 & 42 & 3 & 1 & 0 & 52 & 209 & 4,18 & B \\
\hline & $\mathbf{F}$ & 10 & 88 & 4 & 1 & 1 & 104 & 417 & 4,17 & B \\
\hline & $\%$ & 9 & 85 & 4 & 1 & 1 & 100 & & & \\
\hline \multicolumn{11}{|c|}{ Kemampuan Kerjasama } \\
\hline 9 & $\begin{array}{l}\text { Belum mampu bekerja- } \\
\text { sama dengan rekan kerja }\end{array}$ & 11 & 37 & 3 & 0 & 1 & 52 & 213 & 4,26 & SB \\
\hline 10 & $\begin{array}{l}\text { Jika rekan kerja sedang } \\
\text { kesulitan saya kurang } \\
\text { siap membantu. }\end{array}$ & 9 & 38 & 4 & 1 & 0 & 52 & 211 & 4,22 & SB \\
\hline & $\mathbf{F}$ & 20 & 75 & 7 & 1 & 1 & 104 & 424 & 4,24 & SB \\
\hline & $\%$ & 19 & 72 & 7 & 1 & 1 & 100 & & & \\
\hline & Total Jawaban & 67 & 417 & 23 & 10 & 3 & 520 & & & \\
\hline \multicolumn{2}{|r|}{ Persentase Jawaban (\%) } & $13 \%$ & $80 \%$ & $4,4 \%$ & $2 \%$ & $0,6 \%$ & $100 \%$ & Rata2 & $4,4,19$ & $\overline{\text { B }}$ \\
\hline
\end{tabular}

(Sumber : Data Primer 2018) 
Berdasarkan tabel di atas, penilaian responden atas pernyataan pada variabel Kinerja Perawat $(\mathrm{y})$, yang menjawab sangat setuju, setuju, kurang setuju, tidak setuju dan sangat tidak setuju sebesar $(13 \%+80 \%+4,4 \%+2 \%+0,6 \%)=100 \%$ dengan rata - rata skor 4,19 untuk rentang skala 3.40 - 4.19 dengan kriteria baik.

\section{Hasil Uji Kualitas Data}

1. Hasil Uji Validitas

Pada program SPSS 20 teknik pengujian yang digunakan oleh peneliti untuk uji validitas adalah menggunakan korelasi Bivariate Pearson dengan taraf signifikasi 0,1

\section{a. Uji Validitas Variabel Konflik}

Tabel 3.7 : Hasil Uji Validitas Variabel X1

\begin{tabular}{|c|c|c|c|}
\hline Item Pernyataan & r hitung & r table & Keterangan \\
\hline X1_1 & 0,821 & 0,2329 & Valid \\
\hline X1_2 & 0,797 & 0,2329 & Valid \\
\hline X1_3 & 0,808 & 0,2329 & Valid \\
\hline X1_4 & 0,852 & 0,2329 & Valid \\
\hline X1_5 & 0,895 & 0,2329 & Valid \\
\hline X1_6 & 0,712 & 0,2329 & Valid \\
\hline X1_7 & 0,883 & 0,2329 & Valid \\
\hline X1_8 & 0,900 & 0,2329 & Valid \\
\hline X1_9 & 0,814 & 0,2329 & Valid \\
\hline X1_10 & 0,794 & 0,2329 & Valid \\
\hline
\end{tabular}

Keseluruhan variable konflik mendapat nilai rhitung > rtabel, dapat disimpulkan bahwa semua butir instrumen tersebut valid.

b. Uji Validitas Kecedasan Emosional Variabel (X2)

Tabel 3.8 : Hasil Uji Validitas Variabel X2

\begin{tabular}{|c|c|c|c|}
\hline Item Pernyataan & $\boldsymbol{r}$ hitung & $\mathbf{r}$ table & Keterangan \\
\hline X2_1 & 0,779 & 0,2329 & Valid \\
\hline X2_2 & 0,782 & 0,2329 & Valid \\
\hline X2_3 & 0,753 & 0,2329 & Valid \\
\hline X2_4 & 0,734 & 0,2329 & Valid \\
\hline X2_5 & 0,771 & 0,2329 & Valid \\
\hline X2_6 & 0,778 & 0,2329 & Valid \\
\hline X2_7 & 0,571 & 0,2329 & Valid \\
\hline X2_8 & 0,627 & 0,2329 & Valid \\
\hline X2_9 & 0,624 & 0,2329 & Valid \\
\hline X2_10 & 0,797 & 0,2329 & Valid \\
\hline
\end{tabular}

Keseluruhan variable kecerdasan emosional mendapat nilai $r_{\text {hitung }}>r_{\text {tabel }}$, dapat disimpulkan bahwa semua butir instrumen tersebut valid.

c. Uji Validitas Kinerja Perawat (Y)

Tabel 3.9 : Hasil Uji Validitas Variabel Y

\begin{tabular}{|c|c|c|c|}
\hline Item Pernyataan & r hitung & r table & Keterangan \\
\hline Y_1 & 0,788 & 0,2329 & Valid \\
\hline Y_2 & 0,859 & 0,2329 & Valid \\
\hline Y_3 & 0,747 & 0,2329 & Valid \\
\hline Y_4 & 0,755 & 0,2329 & Valid \\
\hline Y_5 & 0,753 & 0,2329 & Valid \\
\hline Y_6 & 0,672 & 0,2329 & Valid \\
\hline Y_7 & 0,729 & 0,2329 & Valid \\
\hline Y_8 & 0,754 & 0,2329 & Valid \\
\hline Y_9 & 0,773 & 0,2329 & Valid \\
\hline Y_10 & 0,649 & 0,2329 & Valid \\
\hline
\end{tabular}


Kesimpulan dari tabel diatas diketahui bahwa hasil validitas kinerja perawat menunjukan $r$ hitung $>r$ tabel, sehingga setiap pertanyaan dinyatakan valid atau sah dan bisa dilanjutkan untuk penelitian.

\section{Hasil Uji Reliabilitas}

Pengujian reliabilitas pada penelitian ini dilakukan dengan menggunakan metode Alpha-Cronbach dengan menggunakan aplikasi SPSS 20. Setelah dilakukan pengujian menggunakan SPSS 20 maka didapatkan hasilnya sebagai berikut :

Tabel 3.10 : Hasil Uji Reliabilitas

\begin{tabular}{|c|c|c|c|}
\hline Variabel & $\begin{array}{c}\text { Alpha } \\
\text { Cronbach's }\end{array}$ & $\begin{array}{c}\text { Standar Alpha } \\
\text { Cronbach's }\end{array}$ & Keterangan \\
\hline $\mathrm{X} 1$ & 0,949 & 0,60 & Reliabel \\
\hline $\mathrm{X} 2$ & 0,898 & 0,60 & Reliabel \\
\hline $\mathrm{Y}$ & 0,910 & 0,60 & Reliabel \\
\hline
\end{tabular}

Sumber : Hasil uji reliabilitas data primer dengan SPSS 20

\section{Hasil Uji Asumsi Klasik}

a. Uji Normalitas

Tabel 3.11 :Hasil Pengujian Uji Normalitas Kolmogrov One-Sample Kolmogorov-Smirnov Test

\begin{tabular}{|ll|r|}
\hline & & \multicolumn{2}{|c|}{ Unstandardized Residual } \\
\hline Normal & Mean & $0 \mathrm{E}-7$ \\
Normameters & a,b $\quad$ Std. Deviation & 2,07560803 \\
Paramsolute & 090 \\
Most Extreme $\quad$ Positive & 051 \\
Differences $\quad$ Negative &,- 090 \\
Kolmogorov-Smirnov Z &, 646 \\
Asymp. Sig. (2-tailed) &, 798 \\
\hline
\end{tabular}

a. Test distribution is Normal.

b. Calculated from data.

Dari output diatas dapat diketahui bahwa nilai signifikansi (Asymp. Sig 2-tailed) sebesar 0,798. Karena signifikansi lebih dari $0,1(0,798>0,1)$, maka nilai residual tersebut telah normal.

\section{b. Uji Homogenitas}

Tabel 3.12: Hasil Pengujian Uji Homogenitas Test of Homogeneity of Variances

\begin{tabular}{|r|r|r|rr|}
\hline Levene Statistic & \multicolumn{1}{|c|}{$\mathrm{df1}$} & $\mathrm{df} 2$ & Sig. & \\
\hline 3,279 & 11 & 38 & &, 003 \\
\hline
\end{tabular}

Sumber : output data olahan SPSS 20

Dari hasil di atas dapat diketahui signifikansi sebesar 0,003 karena signifikansi lebih dari 0,1 maka dapat disimpulkan bahwa ketiga variabel $\mathrm{X} 1, \mathrm{X} 2$ dan $\mathrm{Y}$ mempunyai varian sama. Angka Levene Statistic menunjukkan semakin kecil nilainya maka semakin besar homogenitasnya.

Tabel 3.13 : Hasil Pengujian Uji Homogenitas

\begin{tabular}{|l|r|r|r|r|r|}
\hline & Sum of Squares & \multicolumn{1}{|c|}{ Df } & Mean Square & F & \multicolumn{1}{c|}{ Sig. } \\
\hline Between Groups & 510,128 & 13 & 39,241 & 6,823 &, 000 \\
Within Groups & 218,545 & 38 & 5,751 & & \\
Total & 728,673 & 51 & & & \\
\hline
\end{tabular}

Sumber : output data olahan SPSS 20 
Dari penghitungan data diatas diperoleh $F$ hitung 6,823 dan dari grafik daftar distribusi $\mathrm{F}$ dengan $d f 1=\mathrm{k}-1+3-1=2$, df2 $=\mathrm{n}-\mathrm{k}=52-3=49$, diperoleh $\mathrm{F}_{\text {tabel }}$ sebesar 2,41. Maka jika $F$ hitung < Tabel $F$ hitung. Hal ini berarti data variabel X1, X2 dan $\mathrm{Y}$ homogen

\section{c. Uji Multikolineritas}

\section{Tabel 3.14 : Hasil Pengujian Uji Multikolineritas} Coefficients $^{a}$

\begin{tabular}{|c|c|c|c|c|c|c|c|}
\hline \multirow[t]{2}{*}{ Model } & \multicolumn{2}{|c|}{$\begin{array}{c}\text { Unstandardized } \\
\text { Coefficients }\end{array}$} & \multirow{2}{*}{$\begin{array}{c}\begin{array}{c}\text { Standardized } \\
\text { Coefficients }\end{array} \\
\text { Beta }\end{array}$} & \multirow[t]{2}{*}{$\mathrm{T}$} & \multirow[t]{2}{*}{ Sig. } & \multicolumn{2}{|c|}{ Collinearity Statistics } \\
\hline & $B$ & Std. Error & & & & Tolerance & VIF \\
\hline (Constant) & 3,154 & 3,183 & & 991 & , 327 & & \\
\hline $\mathrm{X} 1$ & ,273 & ,084 & ,350 & 3,250 & ,002 & ,449 & 2,226 \\
\hline $\mathrm{x} 2$ & ,620 & 117 &, 571 & 5,299 & ,000 & ,449 & 2,226 \\
\hline
\end{tabular}

a. Dependent Variable: $Y$

Uji multikolineritas digunakan untuk mengetahui apakah model regresi ditemukan adanya korelasi antar variabel bebas. Model regresi yang baik seharusnya tidak terjadi korelasi diantara variabel bebas. Multikolineritas dapat diketahui dari nilai tolerance value dan nilai Variance Inflation Factor (VIF). Dari tabel 4.34 Terlihat bahwa nilai tolerance value lebih dari 0,10 dan nilai VIF dari semua variabel dibawah 10 sehingga dapat disimpulkan tidak terjadi multikolineritas diantara variabel-variabel bebas.

\section{Hasil Uji Koefisien Korelasi Berganda}

Hasil uji statistik menggunakan SPSS 20 dapat interpretasikan sebagai berikut:

\section{Tabel 3.15 : Uji Regresi Linear Berganda} Coefficients $^{a}$

\begin{tabular}{|l|r|r|r|r|r|}
\hline \multirow{2}{*}{ Model } & \multicolumn{2}{|c|}{$\begin{array}{c}\text { Unstandardized } \\
\text { Coefficients }\end{array}$} & $\begin{array}{c}\text { Standardized } \\
\text { Coefficients }\end{array}$ & \multirow{2}{*}{ Sig. } \\
\cline { 2 - 4 } & \multicolumn{1}{|c|}{$\mathrm{B}$} & Std. Error & \multicolumn{1}{c|}{ Beta } & & \\
\hline (Constant) & 3,154 & 3,183 & &, 991 &, 327 \\
KONFLIK &, 273 &, 084 &, 350 & 3,250 &, 002 \\
KECERDASAN EMOSIONAL &, 620 &, 117 &, 571 & 5,299 &, 000 \\
\hline \multicolumn{2}{|l|}{ Berdasarkan tabel di atas } \\
\hline
\end{tabular}
persamaan regresinya yaitu:

$$
Y=3,154+0,273(X 1)+0,620(X 2)
$$

Persamaan regresi diatas mempunyai arti :

1. Nilai konstanta (a) sebesar 3,154 artinya meski tanpa adanya pengaruh variabel konflik (X1) dan kecerdasan emosional (X2), maka perawat tetap memiliki tingkat kinerja sebesar 3,154.

2. Variabel Konflik berpengaruh positif terhadap kinerja dengan nilai koefisien sebesar 0,273 artinya bahwa setiap kenaikan konflik (X1) sebesar satu-satuan, maka kinerja perawat $(\mathrm{Y})$ akan meningkat sebesar 0,273 dengan asumsi konflik (X1) dianggap konstan.

3. Variabel kecerdasan emosional berpengaruh positif terhadap kinerja dengan nilai koefisien sebesar 0,620 artinya bahwa setiap kenaikan kecerdasan emosional (X2) sebesar satu-satuan, maka kinerja perawat $(Y)$ akan meningkat sebesar 0,620 dengan asumsi kecerdasan emosional (X2) dianggap konstan. 
JURNAL ILMIAH ILMU MANAJEMEN

\section{E. Analisis Korelasi Berganda}

Tabel 3.16 : Hasil Uji Korelasi

Correlations

\begin{tabular}{|c|c|c|c|c|}
\hline & & KONFLIK & $\begin{array}{c}\text { KECERDASAN } \\
\text { EMOSIONAL }\end{array}$ & $\begin{array}{l}\text { KINERJA } \\
\text { PERAWAT }\end{array}$ \\
\hline \multirow[t]{2}{*}{ KONFLIK } & Pearson Correlation & $\overline{1}$ & ,742" & ,774" \\
\hline & tailed) & 52 & ,000 & , 000 \\
\hline \multirow{2}{*}{$\begin{array}{l}\text { KECERDASAN } \\
\text { EMOSIONAL }\end{array}$} & Pearson Correlation &, $774^{\star \pi}$ & 1 &, $830^{\cdots \times}$ \\
\hline & Sig. (2-tailed) & $\begin{array}{r}, 000 \\
52\end{array}$ & 52 & $\begin{array}{r}, 000 \\
52\end{array}$ \\
\hline \multirow[t]{3}{*}{ KINERJA PERAWAT } & Pearson Correlation &, $774^{* \pi}$ & 830 & 1 \\
\hline & Sig. (2-tailed) &, 000 &, 000 & \\
\hline & $\mathrm{N}$ & 52 & 52 & 52 \\
\hline
\end{tabular}

${ }^{* *}$ Correlation is significant at the 0.01 level (2-tailed).

Tabel diatas untuk hubungan nilai signifikan sebesar $0,000<0,1$, maka dapat disimpulkan bahwa variabel konflik (X1) dan kecerdasan emosional (X2) terhadap kinerja perawat $(Y)$ terdapat hubungan korelasi positif antara konflik dan kecerdasan Emosional terhadap kinerja perawat. Sesuai tabel 4.23 Pearson correlation untuk Konflik dengan Kinerja Perawat sebesar 0,774 yang termasuk kategori kuat. Sedangkan untuk Kecerdasan Emosional dengan Kinerja Perawat sebesar 0,830 yang termasuk kategori sangat kuat.

\section{F. Koefisien Determinasi}

\begin{tabular}{|l|r|r|r|r|}
\hline Model & \multicolumn{1}{|c|}{$\mathrm{R}$} & $\mathrm{R}$ Square & $\begin{array}{c}\text { Adjusted R } \\
\text { Square }\end{array}$ & Std. Error of the Estimate \\
\hline 1 &, $774^{\mathrm{a}}$ &, 598 &, 590 & 2,629 \\
\hline
\end{tabular}

a Predictors: (Constant), KONFLIK

Sumber : output data olahan SPSS 20

Nilai Koefisien $R$ Determinasi $R$ Square sebesar 0,598. Data tersebut mengindikasikan bahwa Konflik terhadap Kinerja Perawat memberikan kontribusi sebesar $59,8 \%$.

Tabel 3.17 : Hasil Uji Kofisien Determinasi Variabel Kecerdasan Emosional (X2) Model Summary

\begin{tabular}{|c|c|c|c|c|}
\hline Model & $\bar{R}$ & R Square & $\begin{array}{c}\text { Adjusted R } \\
\text { Square }\end{array}$ & Std. Error of the Estimate \\
\hline$\overline{1}$ & $830^{\mathrm{a}}$ & ,690 & ,683 & 2,311 \\
\hline
\end{tabular}

a. Predictors: (Constant), KECERDASAN EMOSIONAL

Sumber : output data olahan SPSS 20

Nilai Koefisien $R$ Determinasi $R$ Square sebesar 0,690. Data tersebut mengindikasikan bahwa Kecerdasan Emosional terhadap Kinerja Perawat memberikan kontribusi sebesar $69 \%$.

\begin{tabular}{|l|c|r|r|r|}
\hline Model & $\mathrm{R}$ & $\mathrm{R}$ Square & Adjusted R Square & Std. Error of the Estimate \\
\hline 1 &, $863^{\mathrm{a}}$ &, 745 &, 734 & 2,118 \\
\hline
\end{tabular}

a. Predictors: (Constant), KECERDASAN EMOSIONAL, KONFLIK

Berdasarkan output diatas dapat diperoleh hasil sebagai berikut : 
1. Nilai Koefisien $R$ sebesar 0,863 Artinya korelasi $X 1$ dan $X 2$ terhadap $Y$ sebesar 0,863 antara variabel konflik dan kecerdasan emosional terhadap kinerja perawat.

2. Nilai Koefisien $R$ Determinasi $R$ Square sebesar 0,745. Data tersebut mengindikasikan bahwa konflik dan kecerdaan emosional terhadap kinerja perawat memberikan kontribusi sebesar $74,5 \%$. Sisanya sebesar $25,5 \%$ disebabkan oleh faktor lain diluar penelitian ini.

\section{G. Hasil Uji Hipotesis}

\section{Uji Parsial (Uji t )}

Tabel 3.16 : Hasil Pengujian Uji t Variabel Konflik (X1) Coefficients $^{a}$

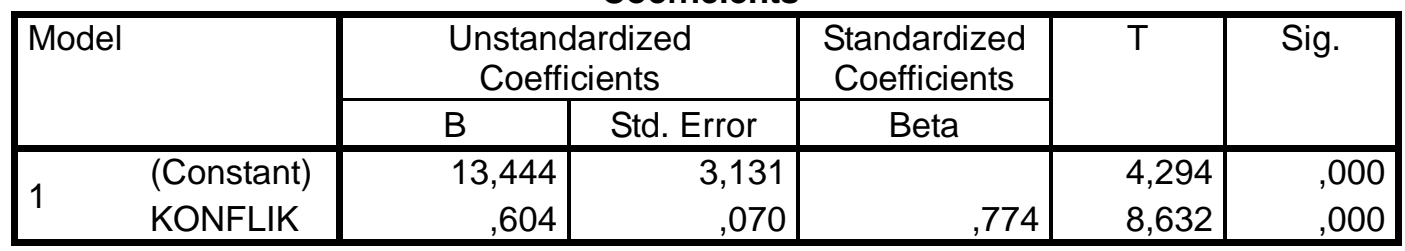

a. Dependent Variable: KINERJA PERAWAT

Sumber : output data olahan SPSS 20

Berdasarkan Tabel di atas pada variabel konflik (X1) diperoleh $t_{\text {hitung }}$ sebesar 8,632 sedangkan $t_{\text {tabel }}$ dengan tingkat signifikasi $10 \%$ dan derajat kebebasan $(\mathrm{dk})=\mathrm{n}-\mathrm{k}=52$ $-3=49$ adalah sebesar 1,676. Dengan melakukan perbandingan yaitu $t_{\text {hitung }}(8,632)>$ $t_{\text {tabel }}(1,676)$ sehingga jatuh pada daerah penerimaan $H_{a}\left(H_{a}\right.$ diterima, $H_{o}$ ditolak). Serta dilihat pada diatas dapat dilihat pula angka signifikasi yaitu $0,000<0,05$, maka dapat ditarik kesimpulan bahwa Konflik secara parsial berpengaruh signifikan terhadap kinerja perawat.

Tabel 3.17 : Hasil Pengujian Uji t Variabel Kecerdasan Emosional (X2) Coefficients $^{\mathrm{a}}$

\begin{tabular}{|c|c|c|c|c|c|}
\hline \multirow[t]{2}{*}{ Model } & \multicolumn{2}{|c|}{ Unstandardized Coefficients } & \multirow{2}{*}{$\begin{array}{c}\begin{array}{c}\text { Standardized } \\
\text { Coefficients }\end{array} \\
\text { Beta }\end{array}$} & \multirow[t]{2}{*}{$T$} & \multirow[t]{2}{*}{ Sig. } \\
\hline & $B$ & Std. Error & & & \\
\hline (Constant) & 3,926 & 3,464 & & 1,133 & ,263 \\
\hline $\begin{array}{ll}1 & \text { KECERDASA } \\
& \mathrm{N} \\
& \text { EMOSIONAL }\end{array}$ & ,903 & 086, & ,830 & 10,542 & ,000, \\
\hline
\end{tabular}

a. Dependent Variable: KINERJA PERAWAT

Sumber : output data olahan SPSS 20

Berdasarkan Tabel di atas pada variabel kecerdasan emosional (X2) diperoleh $\mathrm{t}_{\text {hitung }}$ sebesar 10,542 sedangkan $t_{\text {tabel }}$ dengan tingkat signifikasi $10 \%$ dan derajat kebebasan $(\mathrm{dk})=\mathrm{n}-\mathrm{k}=52-3=49$ adalah sebesar 1,676. Dengan melakukan perbandingan yaitu $\mathrm{T}_{\text {hitung }}(10,542)>\mathrm{T}_{\text {tabel }}(1,676)$ sehingga jatuh pada daerah penerimaan $H_{a}$ ( $H_{a}$ diterima, $H_{o}$ ditolak). Serta dilihat pada tabel diatas dapat dilihat pula angka signifikasi yaitu $(0,000<0,1)$, maka dapat ditarik kesimpulan bahwa kecerdasan emosional secara parsial berpengaruh signifikan terhadap kinerja perawat. 
Tabel 3.18 : Hasil Pengujian Uji t Konflik dan Kecerdasan Emosional Terhadap Kinerja Perawat Wanita

Coefficients $^{\mathrm{a}}$

\begin{tabular}{|c|c|c|c|c|c|c|}
\hline \multirow{2}{*}{\multicolumn{2}{|c|}{ Model }} & \multicolumn{2}{|c|}{$\begin{array}{c}\text { Unstandardized } \\
\text { Coefficients }\end{array}$} & \multirow{2}{*}{$\begin{array}{c}\text { Standardized } \\
\text { Coefficients } \\
\text { Beta }\end{array}$} & \multirow[t]{2}{*}{$\mathrm{T}$} & \multirow[t]{2}{*}{ Sig. } \\
\hline & & $B$ & Std. Error & & & \\
\hline \multirow{3}{*}{1} & (Constant) & 3,154 & 3,183 & & 991 & ,327 \\
\hline & KONFLIK & 273 & ,084 & 3 & 3,250 & ,002 \\
\hline & $\begin{array}{l}\text { KECERDASAN } \\
\text { EMOSIONAL }\end{array}$ & 620, & ,117 &, 57 & 5,299 & ,000 \\
\hline
\end{tabular}

a. Dependent Variable: KINERJA PERAWAT

Berdasarkan tabel di atas pada variabel konflik (X1) diperoleh $t_{\text {hitung }}$ sebesar 3,250 sedangkan $t_{\text {tabel }}$ dengan tingkat signifikasi $10 \%$ dan derajat kebebasan $(\mathrm{dk})=\mathrm{n}-\mathrm{k}=52$ $-3=49$ adalah sebesar 1,676 . Dengan melakukan perbandingan yaitu $t_{\text {hitung }}(3,250)>$ $t_{\text {tabel }}(1,676)$ sehingga jatuh pada daerah penerimaan $H_{a}$ ( $H_{a}$ diterima, $H_{o}$ ditolak).

Berdasarkan Tabel 4.29 diatas pada variabel kecerdasan emosional (X2) diperoleh $t_{\text {hitung }}$ sebesar 5,299 sedangkan $\mathrm{T}_{\text {tabel }}$ dengan tingkat signifikasi $10 \%$ dan derajat kebebasan $(\mathrm{dk})=\mathrm{n}-\mathrm{k}=52-3=49$ adalah sebesar 1,676. Dengan melakukan perbandingan yaitu $T_{\text {hitung }}(5,299)>T_{\text {tabel }}(1,676)$ sehingga jatuh pada daerah penerimaan $H_{a}$ ( $H_{a}$ diterima, $H_{o}$ ditolak). Serta dilihat pada tabel 4.29 diatas dapat dilihat pula angka signifikasi yaitu $(0,000<0,1)$, maka dapat ditarik kesimpulan bahwa Konflik secara parsial berpengaruh signifikan terhadap kinerja perawat

\section{b. Uji F (Uji Simultan)}

Dalam penelitian ini Uji F digunakan untuk mengetahui apakah variable promosi penjualan dan personal selling secara simultan berpengaruh signifikan terhadap variabel keputusan pembelian. Derajat kepercayaan yang digunakan adalah 0,1. Apabila nilai $F$ hasil perhitungan lebih besar daripada nilai $F$ menurut tabel maka hipotesis yang menyatakan bahwa semua variabel independen secara simultan berpengaruh signifikan terhadap variabel dependen. Output hasil uji $f$ dengan SPSS sebagai berikut :

Tabel 3.19 : Hasil Pengujian Uji F ANOVA $^{\mathrm{a}}$

\begin{tabular}{|c|c|c|c|c|c|}
\hline Model & $\begin{array}{c}\text { Sum of } \\
\text { Squares }\end{array}$ & $\mathrm{Df}$ & Mean Square & $\bar{F}$ & Sig. \\
\hline Regression & 640,957 & 2 & 320,479 & 71,472 &, $000^{\circ}$ \\
\hline 1 Residual & 219,716 & 49 & 4,484 & & \\
\hline Total & 860,673 & 51 & & & \\
\hline
\end{tabular}

a. Dependent Variable: KINERJA PERAWAT

b. Predictors: (Constant), KECERDASAN EMOSIONAL, KONFLIK

Sumber : output data olahan SPSS 20

Berdasarkan tabel di atas dapat diketahui bahwa nilai $F_{\text {hitung }}$ sebesar 71,472 sedangkan pada $F_{\text {tabel }}$ dengan signifikasi $10 \%$ dan $d f 1=k-1+3-1=2$, df2 $=n-k=$ $52-3=49$, diperoleh $F_{\text {tabel }}$ sebesar 2,41. Dengan kondisi dimana $F_{\text {hitung }}$ lebih besar dari $F_{\text {tabel }}(71,472>2,41$ dan nilai signifikan lebih kecil dari $a=0,1(0,000<0,1)$, maka 
dapat diambil kesimpulan adalah $H_{\alpha}$ diterima dan $H_{o}$ ditolak yang berarti variabel konflik dan kecerdasan emosional secara simultan berpengaruh signifikan terhadap kinerja perawat.

\section{KESIMPULAN DAN SARAN}

\section{A. Kesimpulan}

Berdasarkan hasil penelitian dan analisis data yang dilakukan dalam penelitian ini mengenai "konflik dan kecerdasan Emosional terhadap kinerja perawat wanita yang sudah menikah di RSUD Dr. Adjidarmo Rangkasbitung", maka penulis menyimpulkan sebagai berikut :

1. Terdapat pengaruh yang positif antara konflik terhadap kinerja perawat dengan hasil $Y=3,154+0,273(\mathrm{X} 1)$, konflik dengan kinerja perawat sebesar 0,774 yang termasuk kategori sangat kuat, konflik terhadap kinerja perawat memberikan kontribusi sebesar $59,8 \%$, dimana hasil $t_{\text {hitung }}$ sebesar 8,632 dengan nilai signifikasi 0,000 . Dengan demikian $t_{\text {hitung }}(8,632)>(1,676)$ dan signifikasi $(0,000)$ $<(0,1)$ yang artinya $H_{a}$ diterima dan $H_{0}$ ditolak. Maka demikian dapat ditarik kesimpulan bahwa terdapat pengaruh yang signifikan dari konflik (X1) terhadap kinerja perawat $(\mathrm{Y})$ pada RSUD Dr. Adjidarmo Rangkasbitung.

2. Terdapat pengaruh yang positif antara kecerdasan emosional berpengaruh positif terhadap kinerja dengan hasil $Y=3,154+0,620(X 2)$, kecerdasan emosional dengan kinerja perawat sebesar 0,830 yang termasuk kategori sangat kuat, kecerdasan emosional terhadap kinerja perawat memberikan kontribusi sebesar $69 \%$, dimana hasil $t_{\text {hitung }}$ sebesar 10,542 dengan nilai signifikasi 0,000 . Dengan demikian $t_{\text {hitung }}(10,542)>(1,676)$ dan signifikasi $(0,000)<(0,1)$ yang artinya $H_{a}$ diterima dan $H_{0}$ ditolak. Maka demikian dapat ditarik kesimpulan bahwa terdapat pengaruh yang signifikan dari kecerdasan emosional (X2) terhadap kinerja perawat (Y) pada RSUD Dr. Adjidarmo Rangkasbitung.

3. Berdasarkan hasil uji hipotesis $F$ yang telah dilakukan dengan menggunakan software IBM SPSS versi 20, dimana hasil $F_{\text {hitung }}(71,472)>F_{\text {tabel }}(2,41)$ dan signifikasi dari konflik (X1) dan kecerdasan emosional (X2) terhadap kinerja perawat (Y) secara bersama-sama (simultan) pada RSUD Dr. Adjidarmo Rangkasbitung. Berdasarkan hasil koefisien determinasi $\left(R^{2}\right)$ diperoleh sebesar 0,745 yang menunjukan bahwa $74,5 \%$ perubahan terjadi pada kinerja $(Y)$ dapat dijelaskan oleh variabel independen konflik (X1) dan kecerdasan emosional (X2) sedangkan sisanya $25,5 \%$ dijelaskan oleh variabel - variabel lain yang belum diketahui dan tidak diteliti didalam penelitian ini. Karena nilai $\mathrm{R}^{2}$ diatas $50 \%$ atau cenderung mendekati nilai 1 maka dapat disimpulkan bahwa kemampuan variabel -variabel independen dalam menjelaskan variabel -variabel cukup mewakili.

\section{B. Saran}

Setelah ditarik kesimpulan dari pembahasan yang telah diuraikan diatas, maka disampaikan saran-saran sebagai pertimbangan di RSUD Dr. Adjidarmo Rangkasbitung sebagai berikut : 
1. Dari hasil pembahasan, perusahaan perlu memperhatikan lagi perawat agar dapat membagi waktu antara pekerjaan dengan keluarga, hal ini dapat dilihat dari jawaban responden yang sedikit waktu nya untuk keluarga dikarenakan waktu libur digunakan untuk bekerja sehingga terjadi lah konflik yang terjadi pada RSUD Dr. Adjidarmo Rangkasbitung.

2. Dari hasil pembahasan, perusahaan perlu memperhatikan lagi perawat supaya bisa mengelola diri dalam mengatur emosi, hal ini dapat dilihat dari jawaban responden bahwa perasaan emosional dapat mempengaruhi pikiran, perkataan dan perbuatan ketika sedang bekerja, sehingga kecerdasan emosional sangat diperlukan pada RSUD Dr. Adjidarmo Rangkasbitung.

3. Dari hasil pembahasan, perusahaan perlu meningkatkan kinerja perawat supaya lebih baik lagi dalam hal waktu bekerja dan menyelesaikan pekerjaan sesuai dengan prosedur, hal ini dapat dilihat dari jawaban responden bahwa pegawai masih banyak yang absen saat jam kerja dan belum dapat menyelesaikan pekerjaan sesuai waktu dan prosedur yang telah ditentukan.

4. Pengaruh konflik dan kecerdasan emosional terhadap kinerja perawat wanita yang sudah menikah sebesar $74,5 \%$, hal ini menunjukan bahwa kondisi variabel bebas harus ditingkatkan lagi walaupun sudah cukup baik hasilnya namum belum optimal. Oleh karena itu disarankan pada penelitian berikutnya agar melakukan penelitian yang relevan dengan cara memperbaiki indikator yang masih tidak baik atau dengan menambah sub indikator pernyataan dan jumlah responden penelitian. Disamping itu, bisa juga dilakukan dengan menambah jumlah variabel bebas yang sesuai.

\section{DAFTAR PUSTAKA}

Appley A, Lawrence dan Lee, Oey Liang. 2010. "Pengantar Manajemen". Jakarta: Salemba Empat.

Arikunto, S. 2010. Prosedur Penelitian Suatu Pendekatan Praktik. Jakarta: Rineka Cipta.

AA. Anwar Prabu Mangkunegara. (2011). Manajemen Sumber Daya Manusia Perusahaan. Bandung: PT. Remaja Rosdakarya.

Adekola, B. (2010). Interferences Between Work And Family Among Male And Female Executives In Nigeria. African Journal of Business Management, 4(6), 10691077.

Bangun, Wilson. 2012. Manajemen Sumber Daya Manusia. Jakarta: Erlangga.

Bohlander, George., and Snell, scott. (2010). Principles of Human Resource. Management, 15th ed. Mason, $\mathrm{OH}$ : South Western-Cengage Learning.

Da Silva Pereira, Belarmino. 2013. "Pengaruh Kompetensi dan Kompensasi Perawat Terhadap Kinerja Perawat di Hospital Nacional Guido Valadares Timor Leste. Tesis Manajemen di Universitas Padjajaran Bandung.

Efendi, V.A. \& Sutanto, E.M., 2013. Pengaruh faktor-faktor pemimpin terhadap komitmen organisasional karyawan di Universitas Kristen Petra. AGORA, 1(1).

Ghozali, Imam. 2011. "Aplikasi Analisis Multivariate dengan Program SPSS". Semarang: badan Penerbit Universitas Diponegoro.

, Imam. 2010. "Aplikasi Analisis Multivariate dengan Program SPSS". Semarang: badan Penerbit Universitas Diponegoro.

Greenhaus, J.H. and Nicholas J. Beutell. 2013. Sources of Conflict Between Work and Family Roles 1 . Acamedy of Management Review.

Goleman, Daniel. 2012. Kecerdasan Emosional mengapa El lebih penting daripada $I Q$ (Alih bahasa: T. Hermaya). Jakarta: Gramedia Pustaka Utama. 
Istijanto. 2009. Aplikasi Praktis Riset Pemasaran. Jakarta: Gramedia Pustaka Utama. Moeheriono. 2012. Pengukuran Kinerja Berbasis Kompetensi. Jakarta: Raja Grafindo Persada.

Marwansyah dan Mukaram. (2010). Manajemen Sumber Daya Manusia. Bandung: Pusat Penerbit Administrasi Niaga Politeknik Negeri Bandung.

Malhotra, Naresh K. (2009). Riset Pemasaran Pendekatan Terapan Jilid 1. Jakarta: PT Index.

Nurita, Meta. 2012. Hubungan Antara Kecerdasan Emosional (EQ) dengan Kinerja Perawat pada Rumah Sakit Umum Pusat Fatmawati Jakarta Selatan. Jakarta: Fakultas Psikologi Universitas Gunadarma.

Prawirosentono, S. 2012. Manajemen Sumber Daya Manusia, Kebijakan Kinerja Karyawan. Yogyakarta: BPFE.

Riduwan. 2012. Skala Pengukuran Variabel-Variabel Penelitian. Bandund: Alfabeta.

Scannel, Mary. (2010). The Big Book of Conflict Resolution Games. United States of America: McGraw - Hill Companies, Inc.

Santoso, Singgih. 2012. Paduan Lengkap SPSS Versi 20. Jakarta: Elex Media Komputindo.

Sugiyono. 2011. Metode penelitian Kuantitatif, Kualitatif dan R\&D. Jakarta: Alfabeta. 2013. Metode Penelitian Binis. Cetakan ke-17. Bandung: Alfabeta. 2013. Metode Penelitian Pendidikan (Pendekatan Kuantitatif, kualitatif dan $R \& D)$. Bandung: Alfabeta.

2012. Memahami Penelitian Kualitatif. Bandung: Alfabeta.

2014. Metode Penelitian Pendidikan (Pendekatan Kuantitatif, kualitatif dan $R \& D)$. Bandung: Alfabeta.

2014. Metode Penelitian Pendidikan (Pendekatan Kuantitatif, kualitatif dan $R \& D)$. Bandung: Alfabeta.

2016. Metode Penelitian Pendidikan (Pendekatan Kuantitatif, kualitatif dan $R \& D)$. Bandung: Alfabeta.

2016. Metode Penelitian Pendidikan (Pendekatan Kuantitatif, kualitatif dan $R \& D)$. Bandung: Alfabeta.

Suwatno \& Priansa, D. 2011. Manajemen SDM Dalam Organisasi Publlik dan Bisnis. Bandung: Alfabeta Bandung.

Syofian Siregar, Metode Penelitian Kuantitatif Dilengkapi Dengan Perbandingan Perhitungan Manual\&SPSS. Jakarta, Prenadaamedia Group. 2010.

Salovey, P., \& Mayer, J. D. Emotional intelligence and regulation of feelings the construction (2010) Applied \& preventive Psychology. Cambridge University Press. Printed in the USA.

Sudjana, Nana. 2012. Penelitian Hasil Proses Belajar Mengajar. Bandung: Remaja Rosda Karya.

Timpe, A. Dale. 2010. Kinerja Sari Ilmu dan Segi Manajemen. Bisnis. Jakarta: Elex Media komputindo.

Terry, George dan Leslie W. Rue. 2010. Dasar-Dasar Manajemen. Cetakan kesebelas. Jakarta: Pt Bumi Aksara.

Wolfman, B.S., 2010. Peran kaum wanita: Bagaiman menjadi cukup dan seimbang dalam aneka peran. Yogyakarta: Kanisius. 